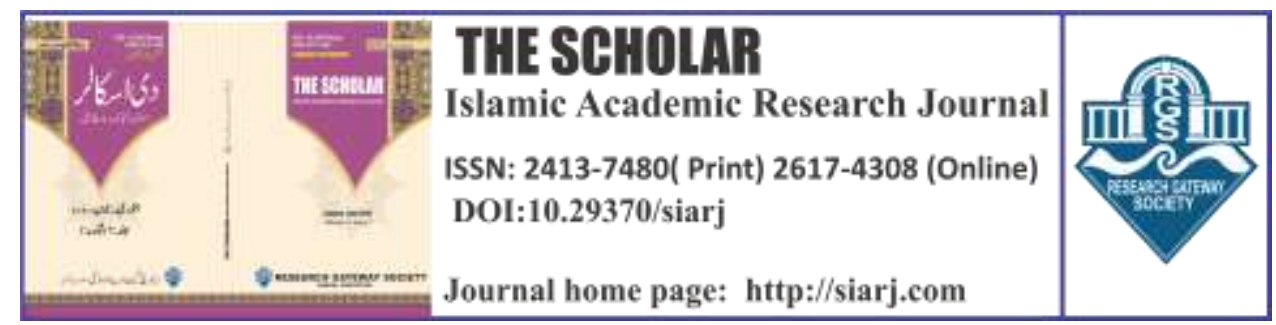

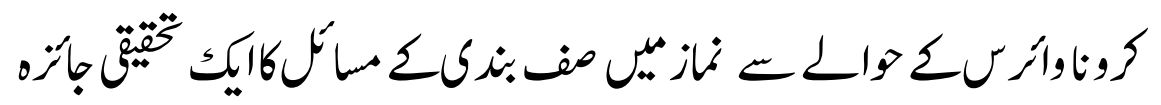

\title{
A RESEARCH ANALYSIS IF MAKING ROWS (SAF) FOR THE CONGREGATIONAL PRAYER WITH REFERENCE TO COVID-19.
}

\section{Syed Naeem Badshah}

Chairman Department of Islamic Studies ,

University of Agriculture Peshawar

Email: syenb@yahoo.com

\section{ORCID ID:}

\section{https://orcid.org/0000-0003-1547-9128}

To cite this article:

Badsha, Syed Naeem, and Ata ur Rahman. "A RESEARCH ANALYSIS IF MAKING ROWS (SAF) FOR THE CONGREGATIONAL PRAYER WITH REFERENCE TO COVID-19." The Scholar-Islamic Academic Research Journal 6, No. 1 (May 29, 2020): 85-94.

To link to this article: https://doi.org/10.29370/siarj/issue10ar17

\begin{tabular}{|c|c|}
\hline Journal & The Scholar Islamic Academic Research Journa \\
\hline & Vol. 5, No. 1 || January -June 2020 || P. 85-94 \\
\hline Publisher & Research Gateway Society \\
\hline DOI: & 10.29370/siarj/issue10ar16 \\
\hline$\underline{\text { URL: }}$ & https://doi.org/10.29370/siarj/issue10ar17 \\
\hline License: & Copyright c 2017 NC-SA 4.0 \\
\hline Journal homepage & www.siari.com \\
\hline Published online: & 2019-05-31 \\
\hline
\end{tabular}
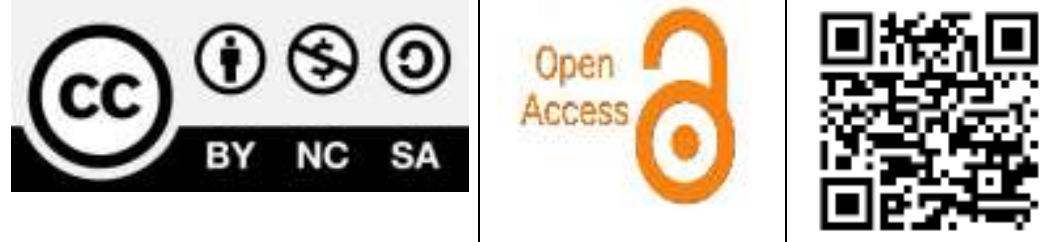
THE SCHOLAR (January - June 2020)

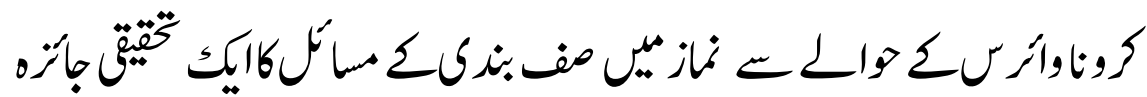 \\ A RESEARCH ANALYSIS IF MAKING ROWS (SAF) FOR THE CONGREGATIONAL PRAYER WITH REFERENCE TO COVID-19.
}

Syed Naeem Badshah, Ata ur Rahman

\begin{abstract}
:
Making and properly straightening of rows (Saf) is integral part of congregational prayers. The rows can either be physically jointed or can be implied in case people have to stand in a distance for example people offering prayer inside and outside the prayer hall. The important thing is to be under proper discipline while making rows for prayer. There should not be any unnecessary gap in the rows. But it is permitted in case if inevitability. Unnecessary gap is considered to be Tahrim Takrihi. Now a day it has emerged as a big issue in wake of the prevailing pandemic; COVID-19. Scholars are if the opinion that it us not only permitted to observe medical instruction while making rows for prayer but it is the desired and suggested option under the circumstances. This is because the current Pandemic can speedily spread in case social distancing is not practiced. The current article will focus on this issue in detail.
\end{abstract}

KEYWORDS: COVID-19, MAKING ROWS (SAF), Prayer, Pandemic,

Jurisprudential rules

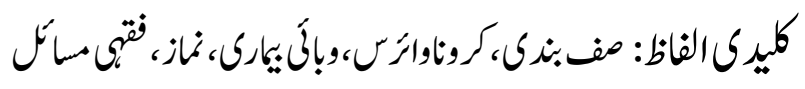




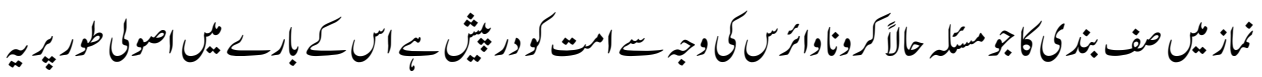

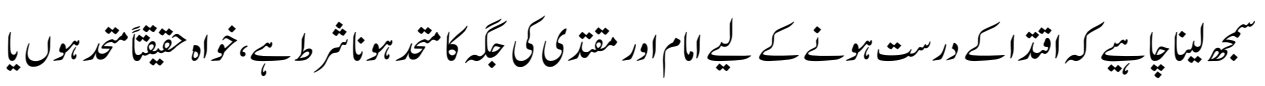

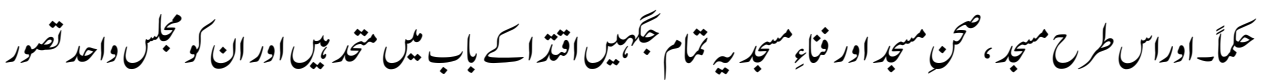

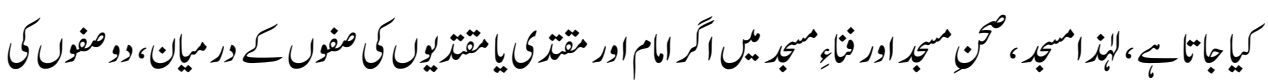

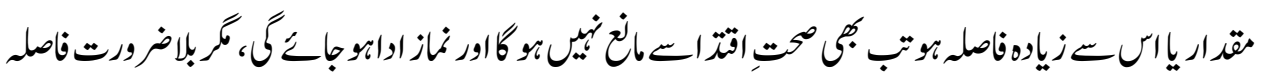

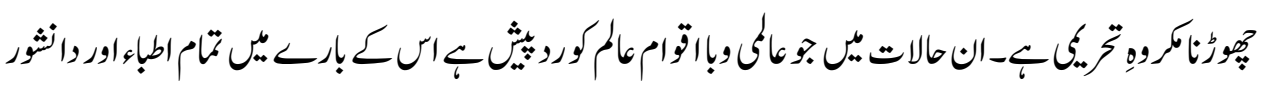

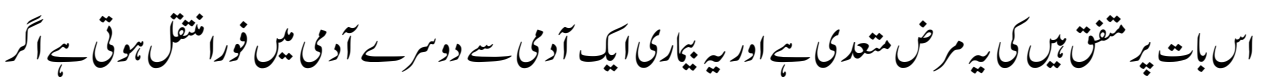

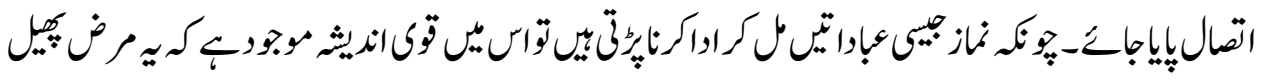

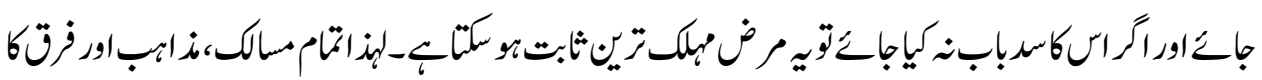

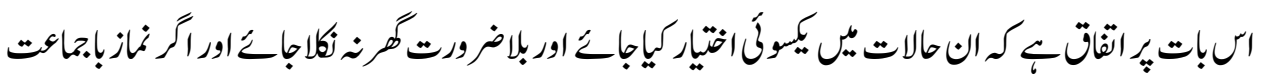

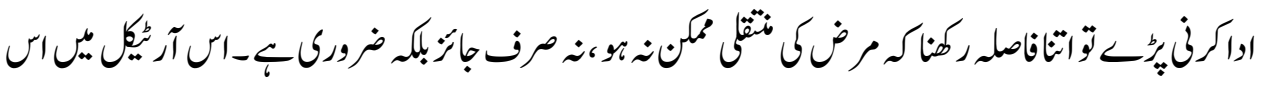

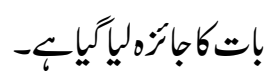
:

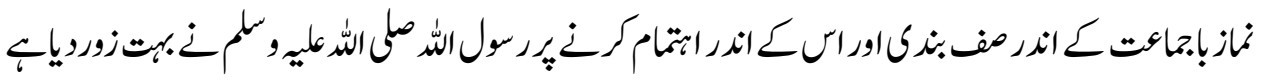

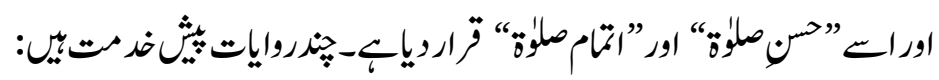

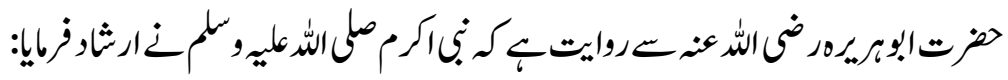

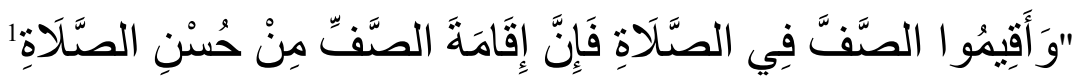

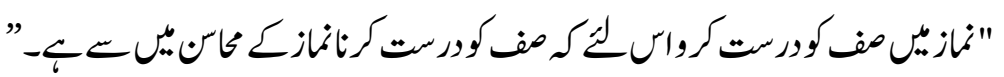

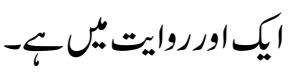

\footnotetext{
${ }^{1}$ Al-Bukhari, Muhammad ibn Isma'il, Al-Jami 'al-Sahih: Volumul 1, page no 100 , Bab lqamatul Safmin tamam al Salah, Dar Tawq al Nijah, 1422 AH.
} 


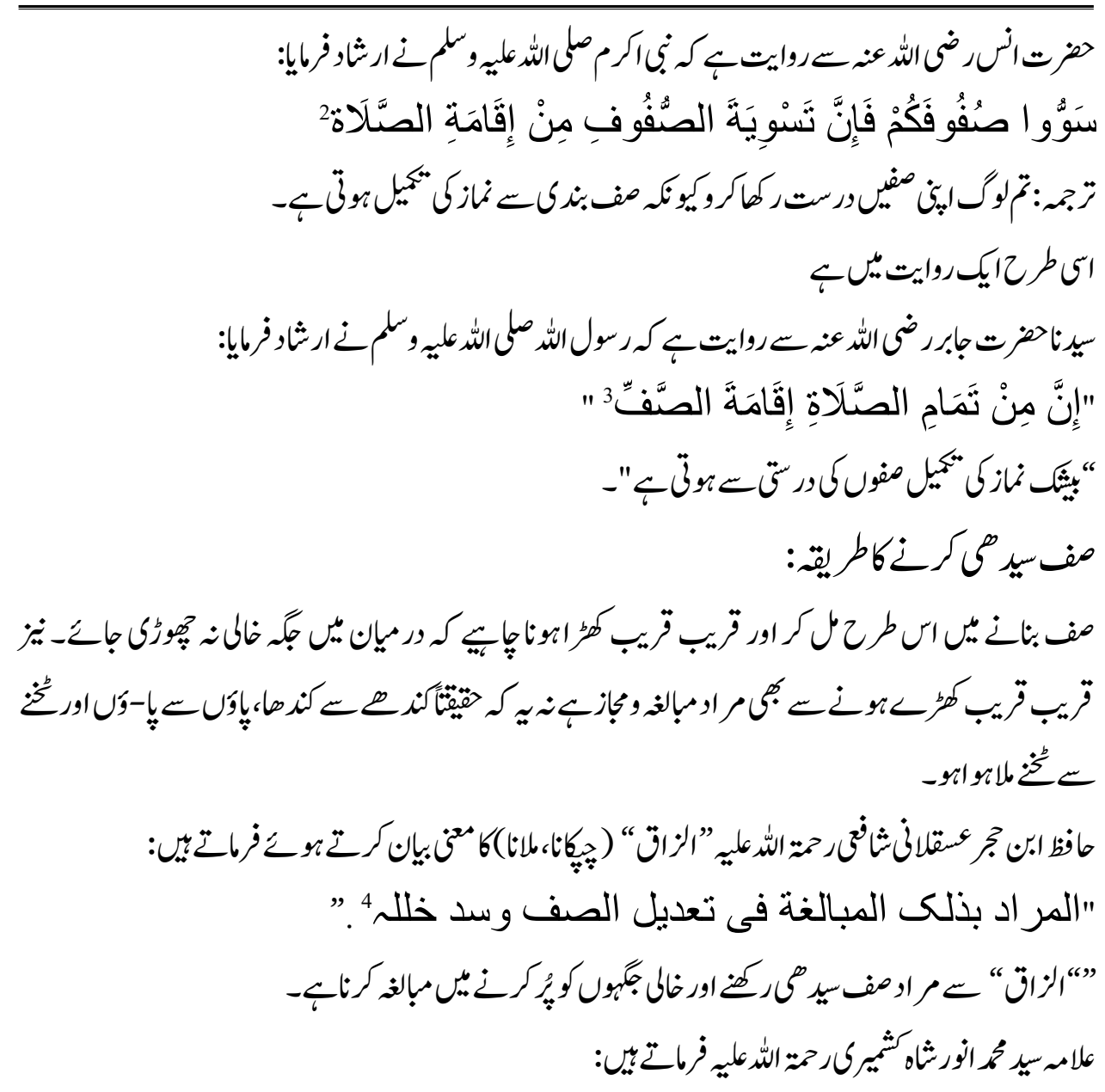

"قال الحافظ المر اد بذلك المبالغة في تعديل الصف وسد خلله. قلتُ: و هو المراد عند الفقهاء الاربعت اى ان لا يترك فى البين فرجت تسع فبها ثالث5

2 Al-Bukhari, Muhammad Ibn Ismail, Sahih Al-Bukhari: Volumul 1, page no 100, Bab lqamatul Safmin tamam al Salah, Dar Tawq al Nijah, $1422 \mathrm{AH}$.

${ }^{3}$ Ibn Hanbal, Abu Abdullah Ahmad ibn Muhammad, Musnad Ahmad, Tahaqiq, Ahmad Shakir, 22 p. 346 Hadith number 14454 Dar al-Hadith, Beirut, 1416 AH.

${ }^{4}$ Al-Asqalani, Ibn Hajar, Fateh al-Bari: vol. 2, p. 273, Dar Kitab al Ilmia, Bairut, $1414 \mathrm{AH}$.

${ }^{5}$ Faiz Al-Bari al Sahih Al-Bukhari lil Kashmiri: Vol: 2, p: 236, I: Dar Al-Kitab AlAlamiya Beirut, $\mathrm{AH} 1422$. 


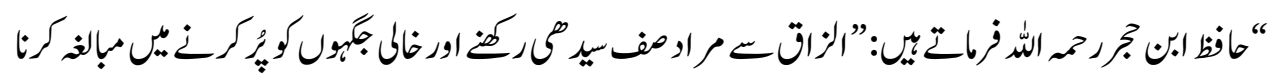

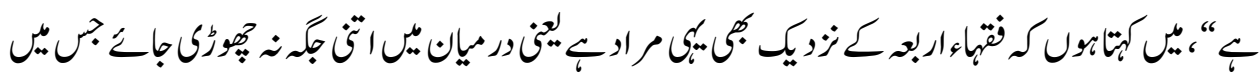

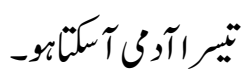

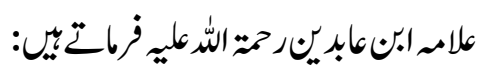

"وما روي أنهم ألصقو ا الكعاب بالكعاب أريد به الجماعة أي قام كل و احد

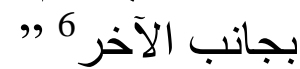

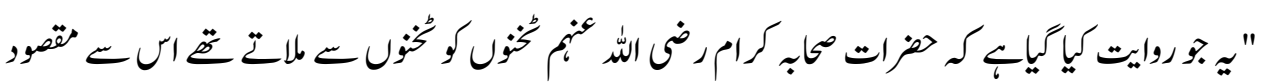

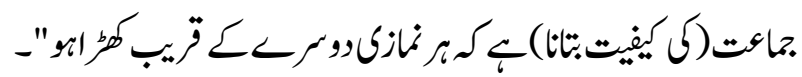

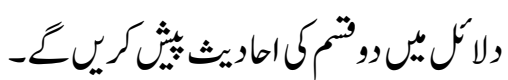

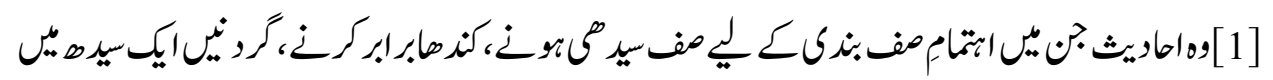

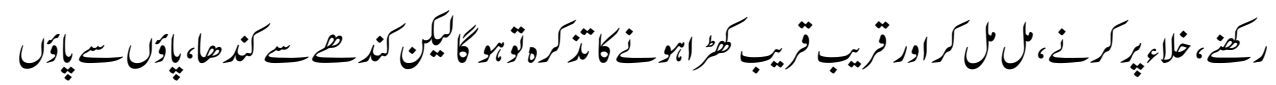

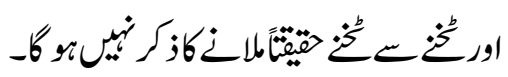

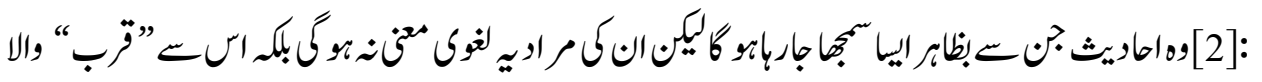

$$
\text { اطنز }
$$

"عن نعمان بن بشير يقول: كان رسول اللّ صلى الله عليه و سلم يسوى

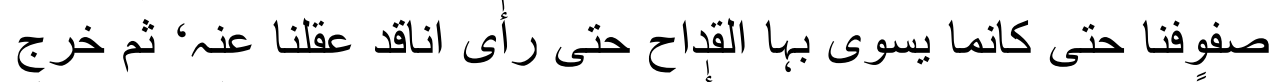

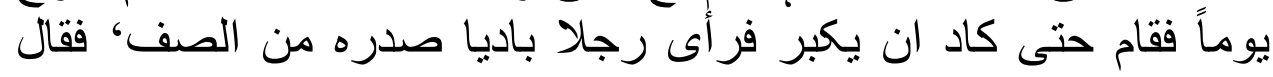

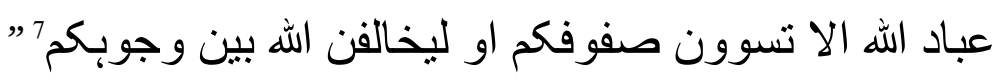

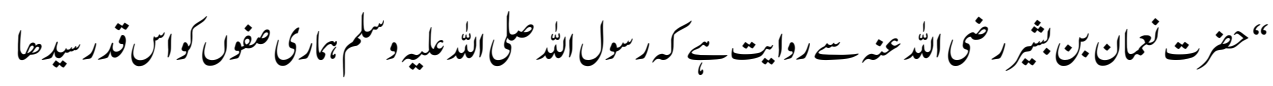

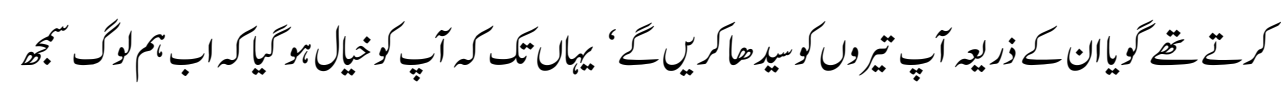

${ }^{6}$ Rad al-Muhtar, Allama Ibn Abidin, Kitab al-Hazr wa al-Abah, vol. 2, p. 163, H. M. Saeed, Karachi, 1999.

${ }^{7}$ Al-Qushayri, Musulim Ibn Hajjaj, Sahih Muslim, Tahaqiq, Muhammad Fouad Abd Al-Baqi, 1/182 Dar Al-Ahyaa Al-Tarath Al-Arabi, Beirut 1420 AH 


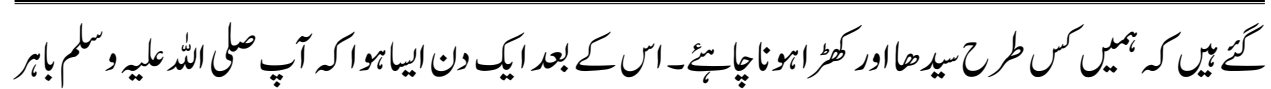

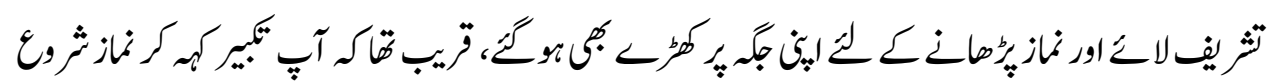

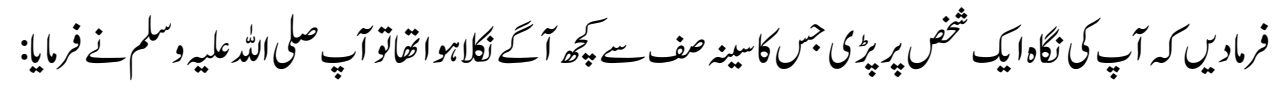

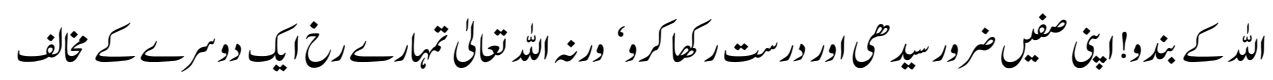
كروبـان

"عن ابن عمر رضىى الله عنم ان رسول الله صلى الله عليه و سلم قال: اقيموا الصفوف وحاذوا بين المناكب وسدو ا الخلل ولينو ا بايدى اخو انكم ولاتذروا فرجات للثيطان ومن وصل صفّا وصله الله ومن قطع صفّا قطع الهه 8

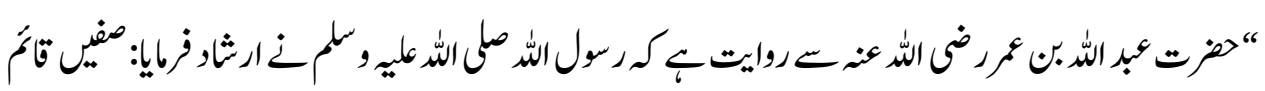

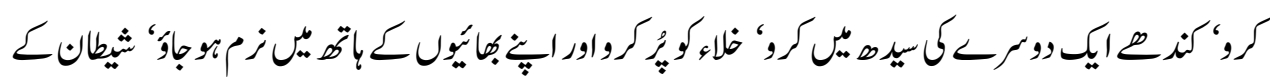

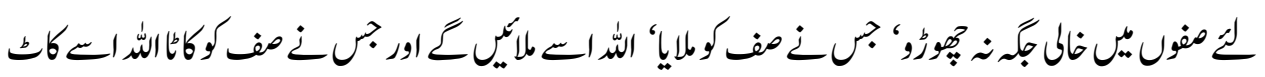

"عن البراء بن عازب رضى الله عنه قال: كان رسول الله صلى الله علي و سلم يتخلل الصف من ناحية يمسح صدورنا ومناكبنا ويقول لاتختلفوا

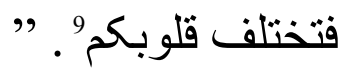

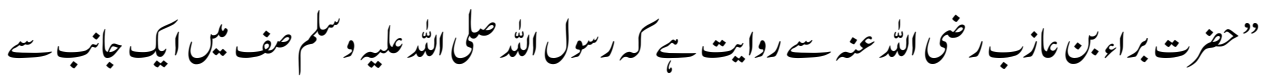

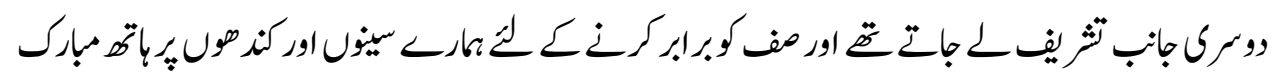

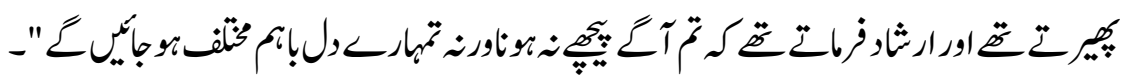

${ }^{8}$ Al-Sujistani, Sunan Abi Dawood, Tahaqiq, Shoaib Al-Arnaout, vol. 1, p. 104, Bab Taswia al Sufoof, Dar al Risalah al IImiah, $1430 \mathrm{AH}$.

${ }^{9}$ Al-Sujistani, Sunan Abi Dawood Abi Dawood: Volumul 1, Page no 104, Bab Taswia al Sufoof, Dar al Risalah al IImiah, $1430 \mathrm{AH}$ 
“ؤن انس بن مالك انم قدم المدينة“فقيل لـ ما انكرت منا منذ يوم عبدت رسول الله صلى الله عليم و سلم قال ما انكرت شيئا الا انكم لايقيمون الصفوفـ10

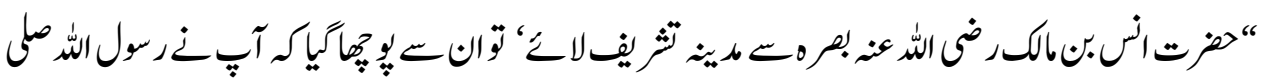

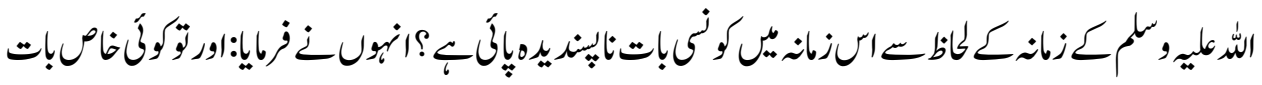

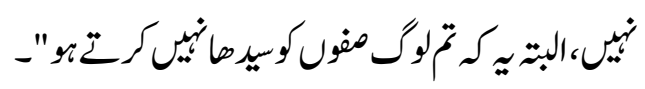

"عن بلال رضـى الله عنم قال: كان النبى صلى الله علبه و سلم بسوى مناكبنا فى الصلاة

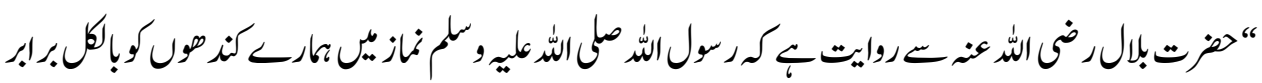
كرع

"وروى عن عمر انـ كان يؤكل رجلا باقامة الصف و لايكبر حتى يخبر ان الصفوف قد استوت، وروى عن علىّ وعثمان، انهما كانا بتعابدان ذلك ويقو لان استوو اوكان علىّ يقول تقدم يا فلان، تاخر يافلان 12.

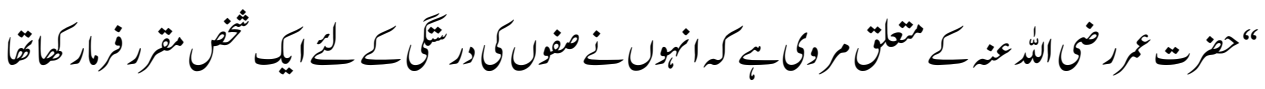

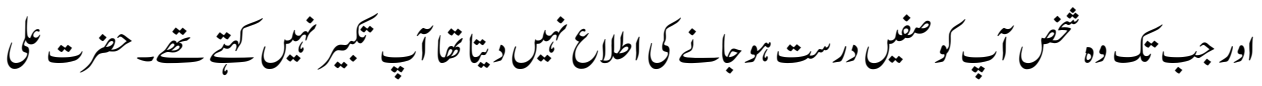

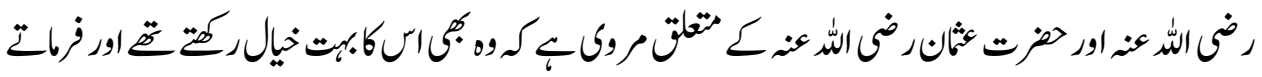

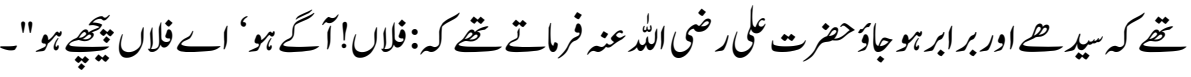

${ }^{10}$ Al-Bukhari, Muhammad ibn Isma'il Sahih Bukhari: Volumul 1, Page no 100, Bab Ism man lam yatim al Sufoof, Dar Tawq al Nijah, $1422 \mathrm{AH}$.

${ }^{11}$ Al-Tabarani, Qasim Ibn Salman, Al Mu'jam al Saghir li Tabarani: vol. 2, p. 81, Maktab al-Rashd, Beirut, 1994;

${ }^{12}$ Al-Tirmidhi, Muhammad ibn Isa, Sunan al-Tirmidhi, Tahqiq wa Ta'liq, Ahmad Muhammad Shakir Muhammad Fouad Abd al-Baqi, vol. 1, p. 53, Bab Ma Jaa fi Iqamatul Sufoof , Matba' Mustafa al Hulabi, Egypt,1395 AH 
THE SCHOLAR (January - June 2020)

"عن مالك بن ابى عامر الانصارى ان عثمان بن عفان كان يقول فى

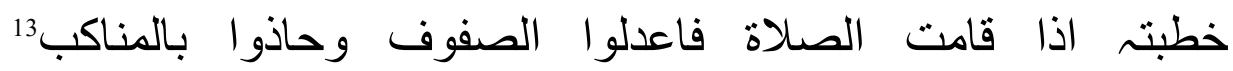

${ }^{13}$ Malik, Anas bin Malik, Mu'ta Imam Muhammad: $p$ 88, Bab Taswia al Sufoof, Darul Riyan, Bairut, 1993. 


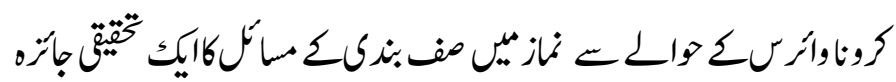

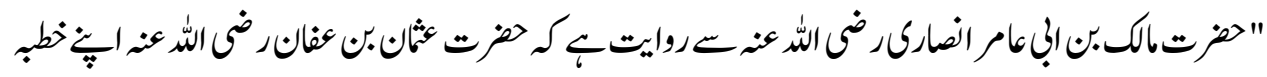

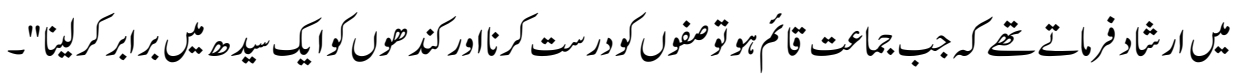

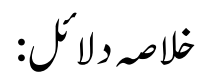

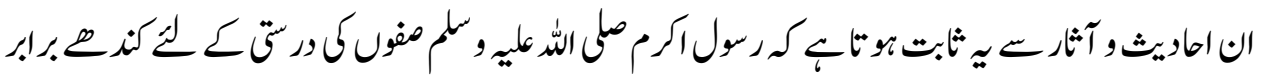

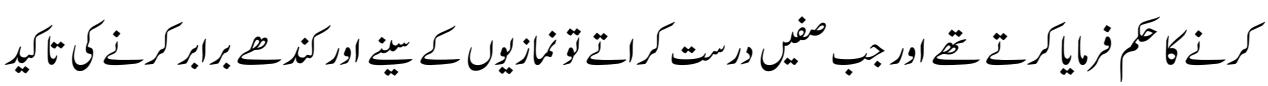

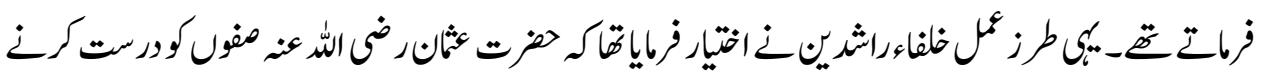

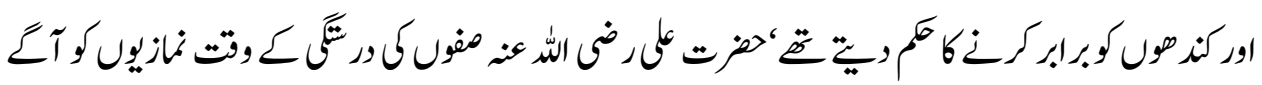

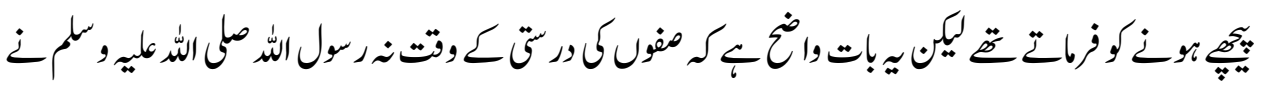

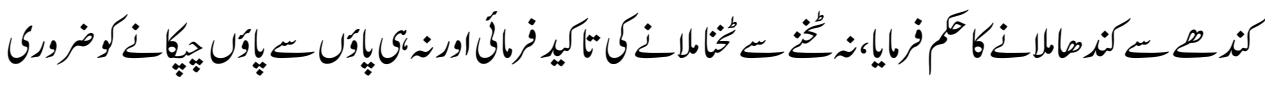

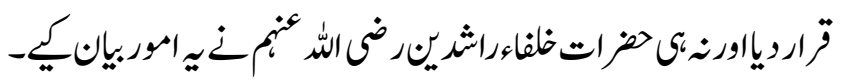

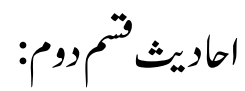

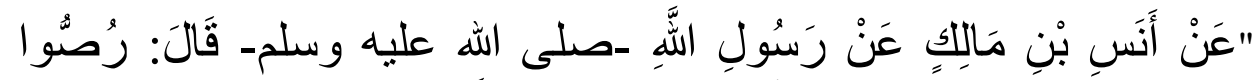

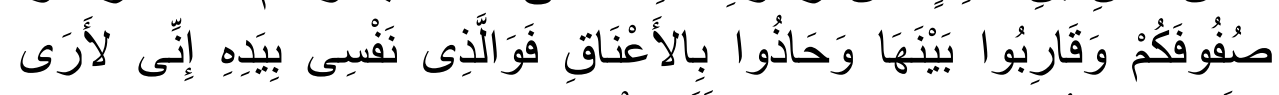

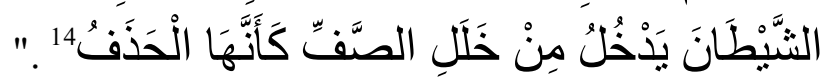

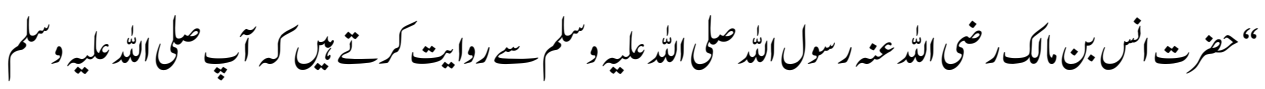

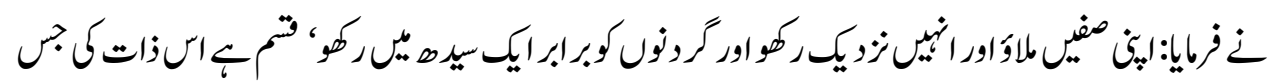

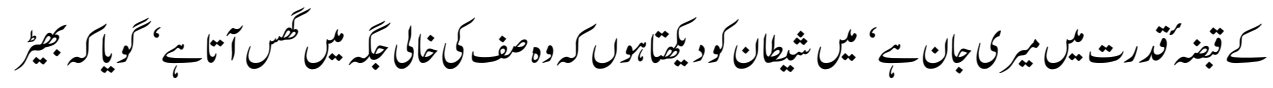

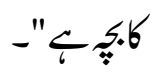

"عن ابن عباس رضى الله عنه قال: قال رسول الله صلى الله عليه و سلم

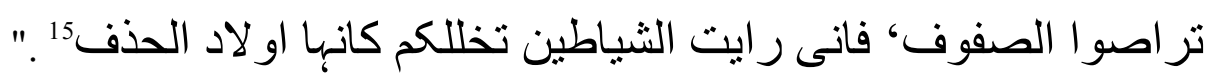

${ }^{14}$ Al-Sujistani, Sunan Abi Dawood Abi Dawood: Volumul 1, Page no 104, Bab Taswia al Sufoof, Dar al Risalah al Ilmiah, $1430 \mathrm{AH}$.

${ }^{15}$ Majma' Al-Zawaid: Vol. 2, p. 251, Bab Silatul Sufoof wa Sadul Furaj, 


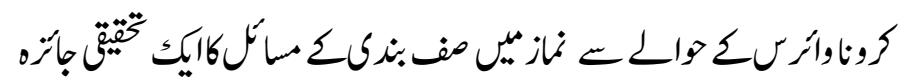

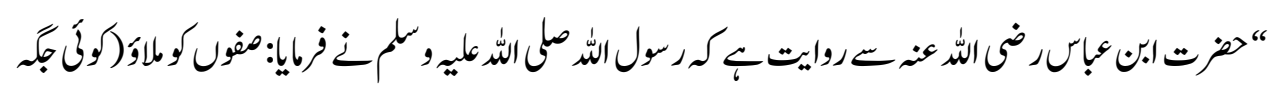

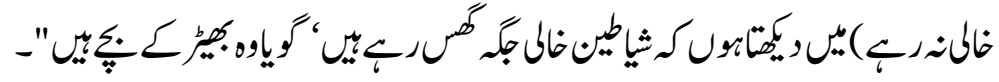

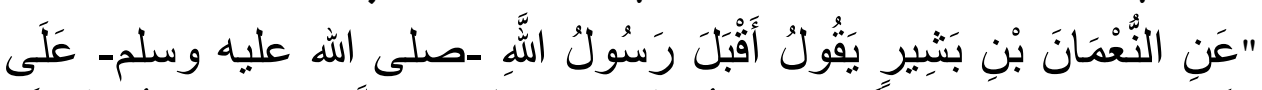

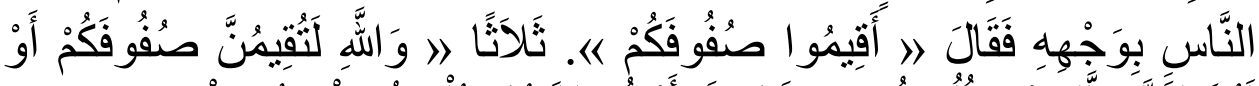

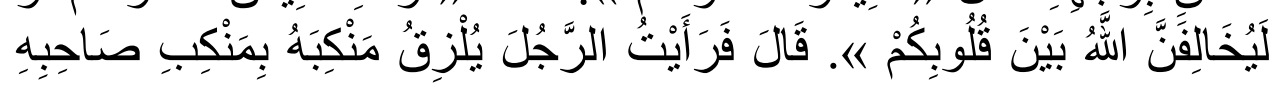

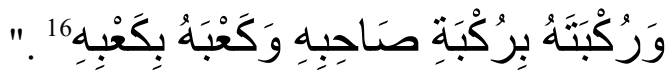

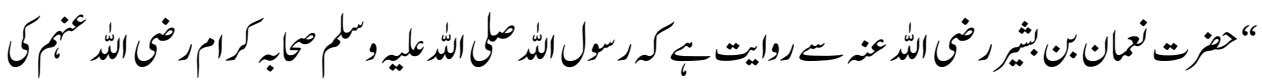

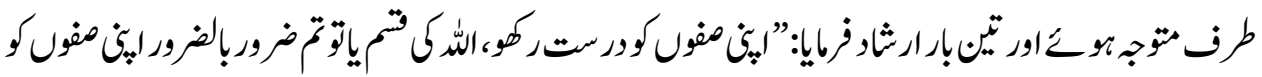

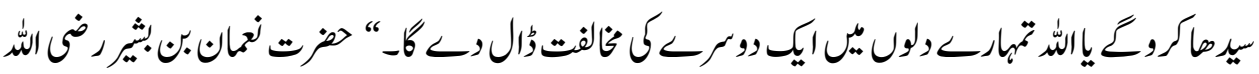

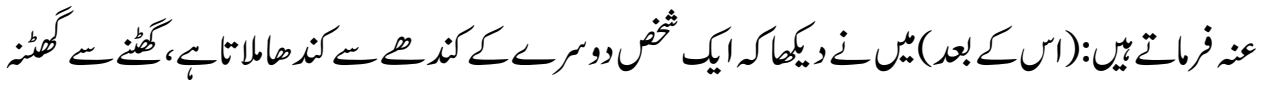
اوربن فائره:

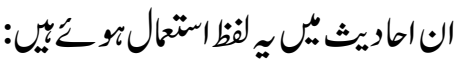

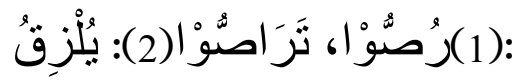

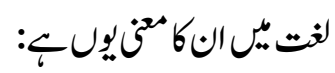

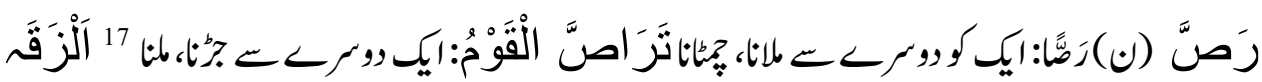
${ }^{18} 8$

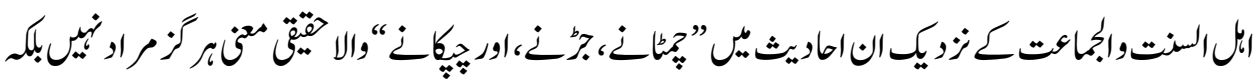

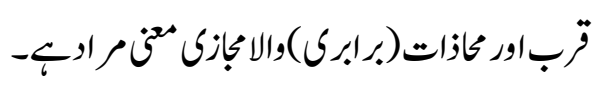

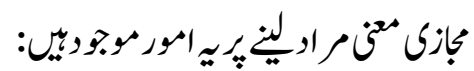

${ }^{16}$ Al-Sujistani, Sunan Abi Dawood Abi Dawood: Volumul 1, Page no 104, Bab Taswia al Sufoof, Dar al Risalah al IImiah, $1430 \mathrm{AH}$.

${ }^{17}$ Louis Maalouf, Al-Munajjid, p. 387, Nashriat e Islam, Karachi, 2008

${ }^{18}$ Louis Maalouf, Al-Munjid: p. 919, Nashriat e Islam, Karachi, 2008. 


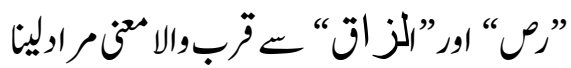

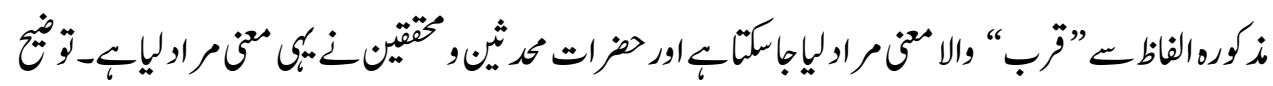
ثيثن خمتشب:

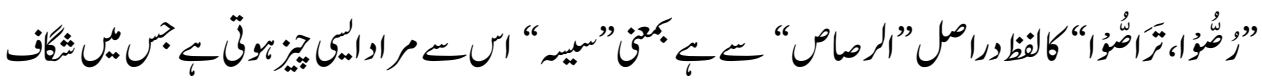

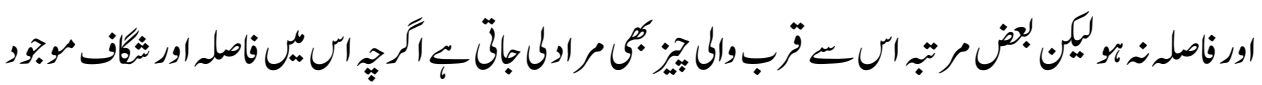

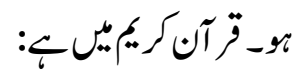

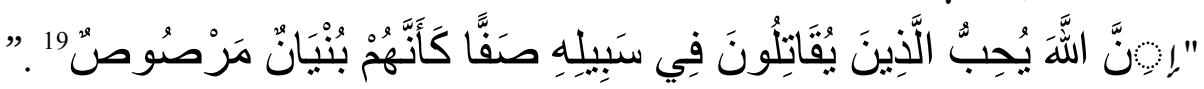

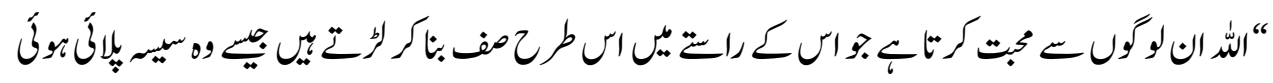

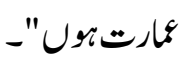

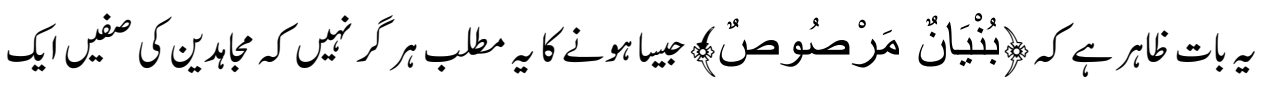

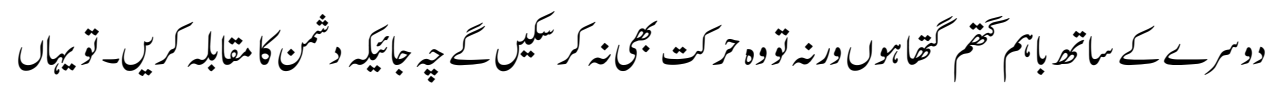

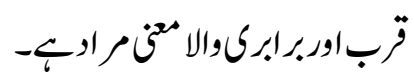

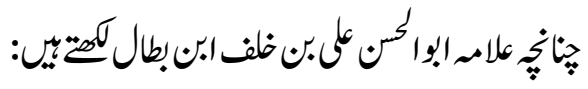

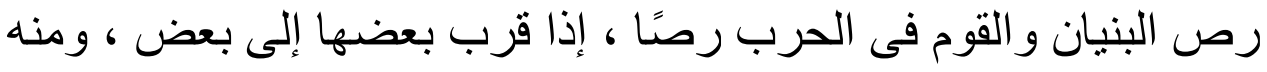

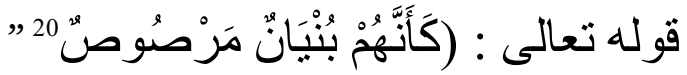

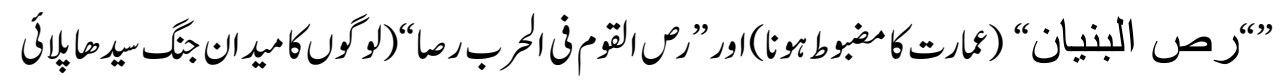

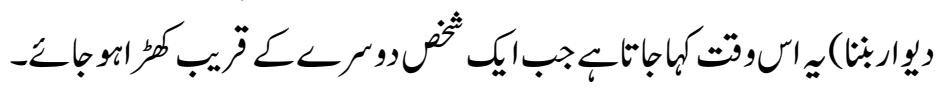

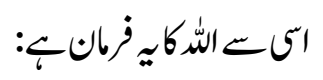

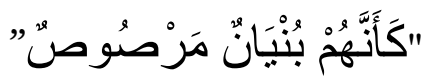

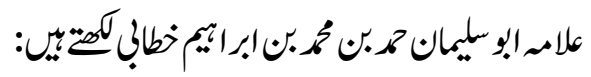

\footnotetext{
${ }^{19}$ Surah Saff: 4

${ }^{20}$ Ibn Batal, Abu al-Hasan Ali ibn Khalaf ibn Abd al-Mulk ibn Batal al-Qurtubi Sharh Sahih al-Bukhari Ibn Batal: vol. 9 p. 334, Maktab al-Rashd 2008
} 


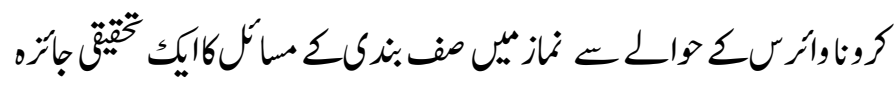

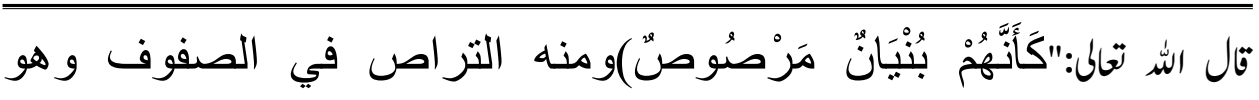
التقارب

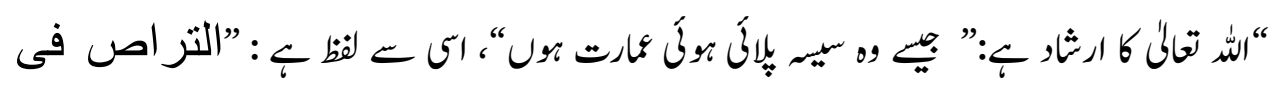

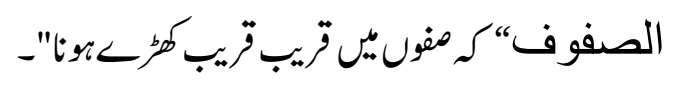

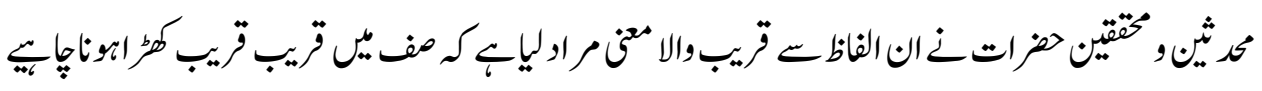

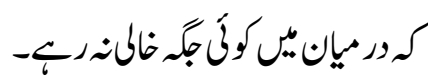

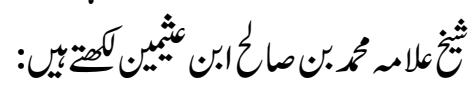

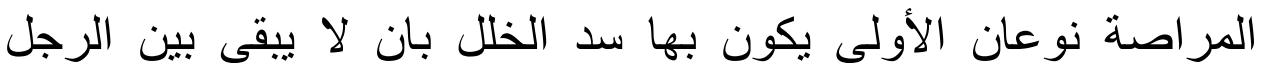

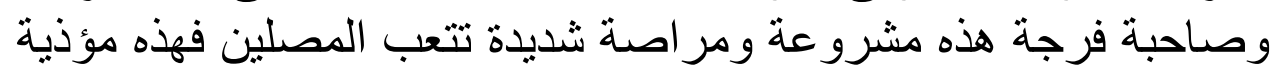

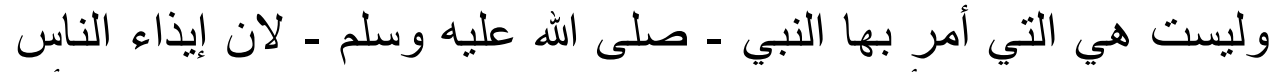

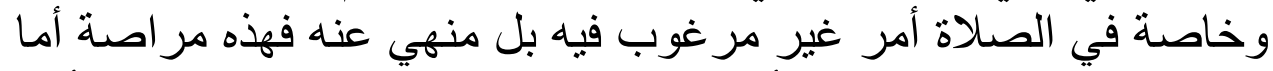
قوله قاربوا بينها فالمعنى أن يقرب الصف الثف الثاني من الصف الأول

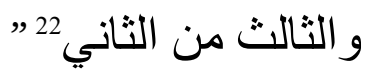

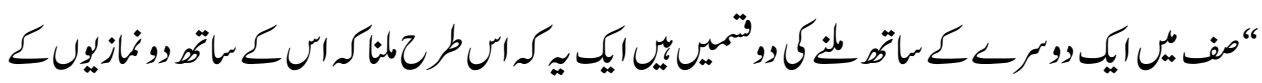

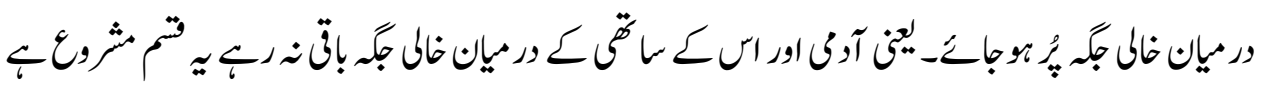

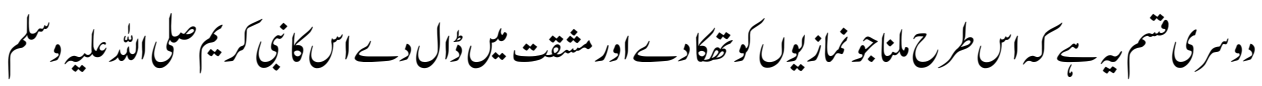

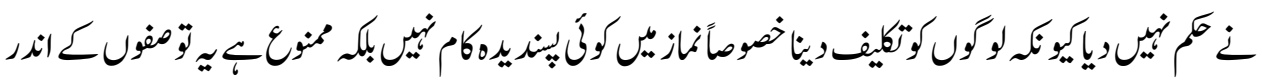

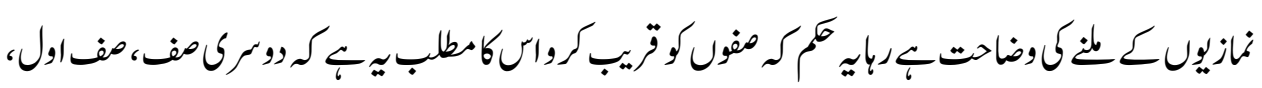

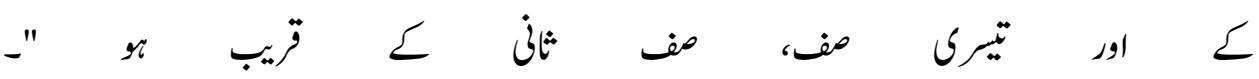

${ }^{21}$ Lil Khatabi, Ghareeb al-hadith : 634, ghareeb al-hadith Tahqeeq Abdul Alkrim Al Ghurabavi, Daar al Ifkr, Dimashq 1982.

${ }^{22}$ Muhammad Bin Saleh Al-Uthaymeen - Sheikh Muhammad Bin Saleh AlUthaymeen Moassasah Al-Qassim lil Khairia, Al Qasim, Al Saudia, Volumul 2, $1440 \mathrm{AH}$. 


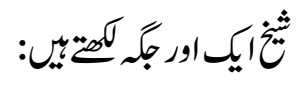

"ليس المر اد بالمر اصة المر اصة التي تشوش على الآخرين و إنما المر اد

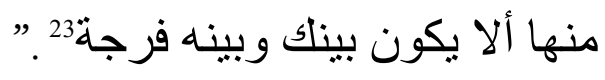

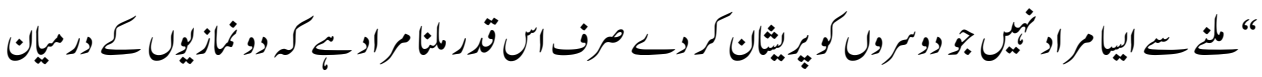

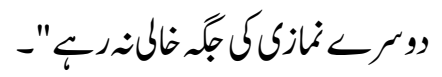

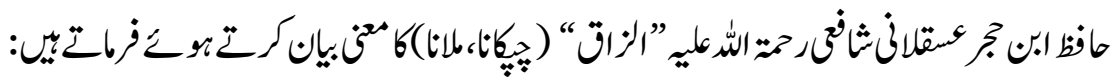

"المر اد بذلى المبالغة فى تعديل الصف وسد خللـ24.

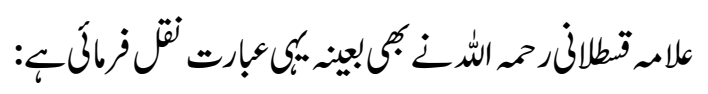

"المر اد بذلك المبالغة فى تعديل الصف وسد خللـ"25."

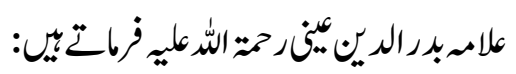

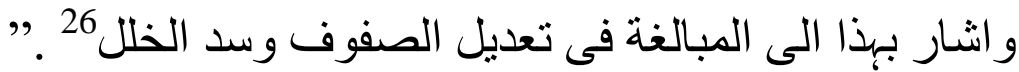

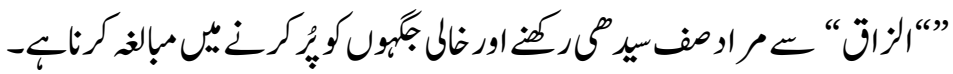

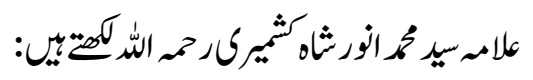

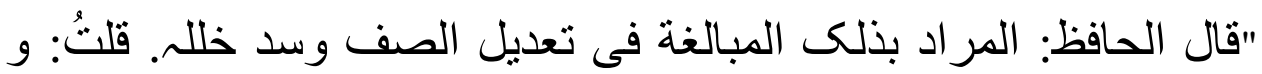
هو مر اده عند الفقبهاء الاربعت ای ان لا يترك فى البين فرجت تسع فيها فيها ثنالثا27.

${ }^{23}$ Al-Uthman, Shaykh Allama Muhammad ibn Saleh Ibn Uthaymeen Sharh Riyadh al-Saliheen: vol. 1 p. 1448, Riyadh alSaudia

${ }^{24}$ Al-Asqalani, Ibn Hajar, Fath al-Bari: vol. 2, p. 211, Dar al-Kitab al-Alamiya, Beirut, $1415 \mathrm{AH}$.

${ }^{25}$ Al-Qastalani, Shahab al-Din Abu al-Abbas Ahmad ibn Muhammad, Rashad alSari, Sharah li Sahih al-Bukhari, vol. 2, p. 368, Dar al-Fikr, Beirut, 1972.

${ }^{26}$ Al A'ini, Badruddin Al A'ini, Umda Al-Qari Sharh Al-Sahih Al-Bukhari, Volumul 4, Pagina 360, Maktab Rashidia Quetta

${ }^{27}$ Faiz al-Bari li Sahih al-Bukhari lil Kashmiri: vol. 2, p. 236 


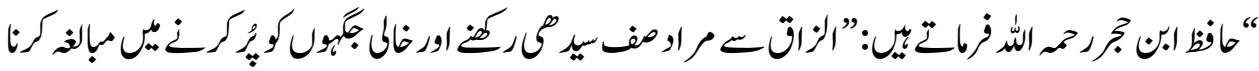

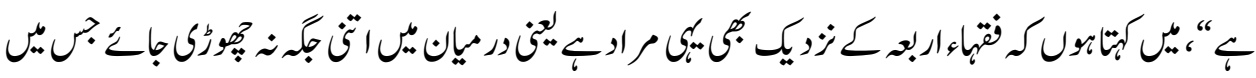

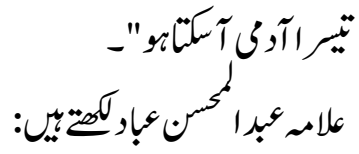

"أن كل و احد يقرب من صاحبه حتى يلتصق بهاه، وحتى يكون متصلاً بها،

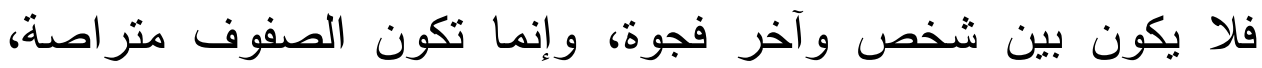

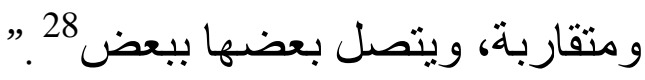

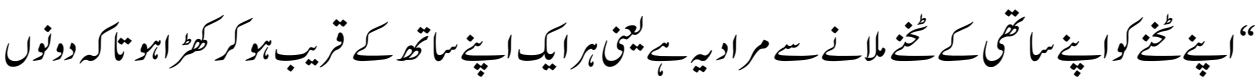

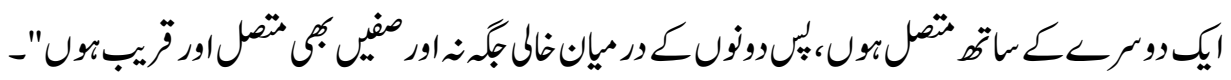

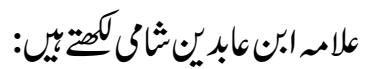

"وما روي أنهم ألصقو الكعاب بالكعاب أريد به الجماعة أب قام كل و احد بجانب الآخر 29.

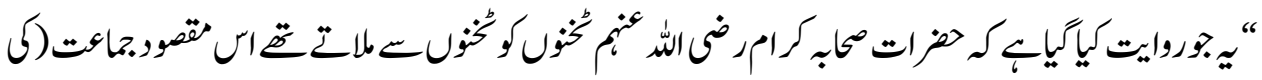

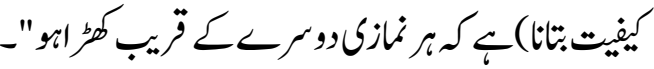

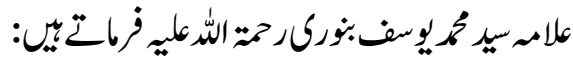

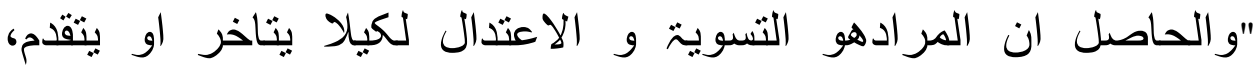
فالمحاذاة بين المناكب و الزاق الكعاب كنايت عن التسويت30"

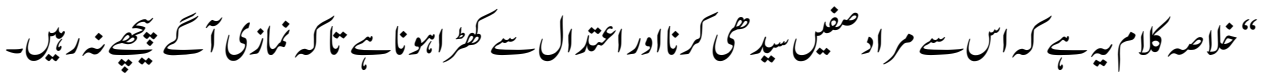

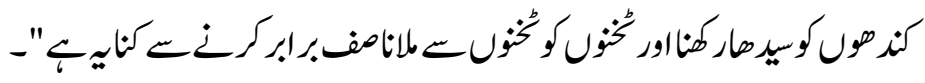

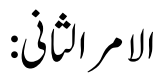

${ }^{28}$ Al-Sujistani, Sunan Abi Dawood Abi Dawood: Volumul 1, Page no 104, Bab Taswia al Sufoof, Dar al Risalah al IImiah, $1430 \mathrm{AH}$.

${ }^{29}$ Radul Mukhtar, lil Allama Ibne A'bidin, v2, P. 163, Bahs al Qiam.

${ }^{30}$ Al Binori, Muhammad Yousuf al Binori, Ma'rif al Sunan Sharah Jamia' Tarmizi, v2, p 297,298, H M Saeed, Karachi. 


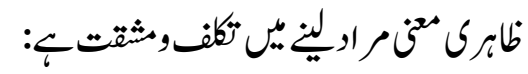

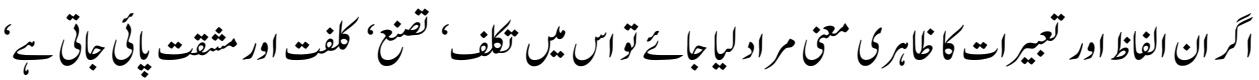

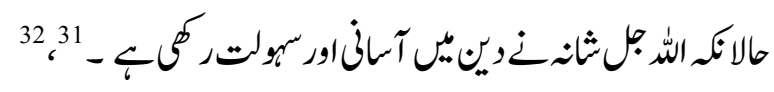

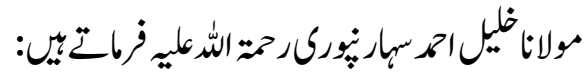

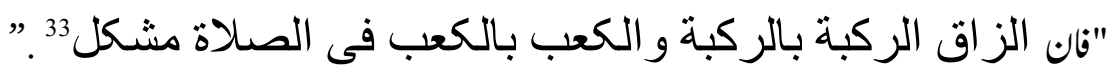

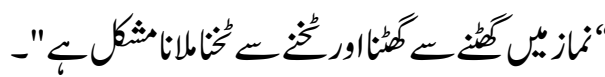

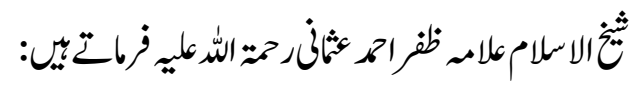

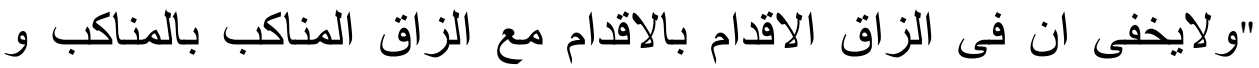

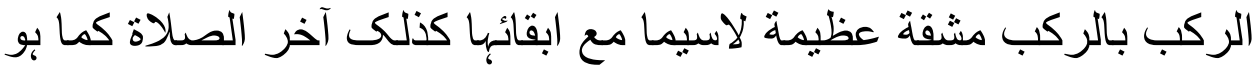

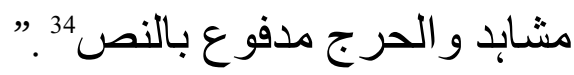

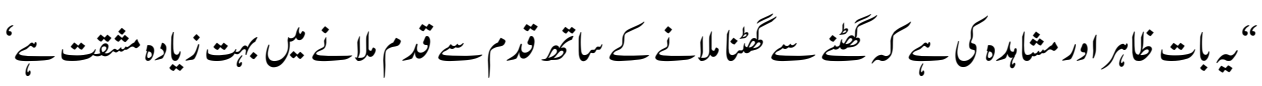

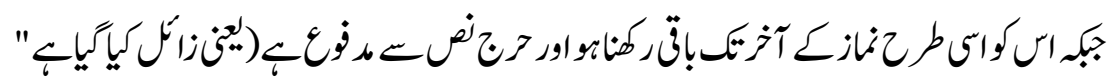

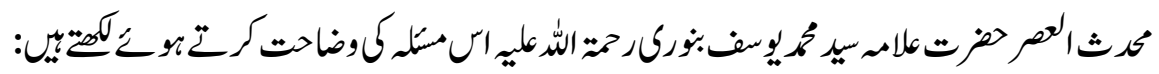

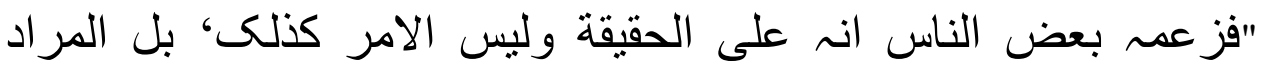

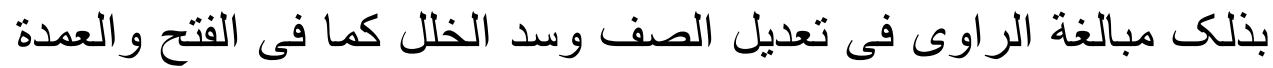

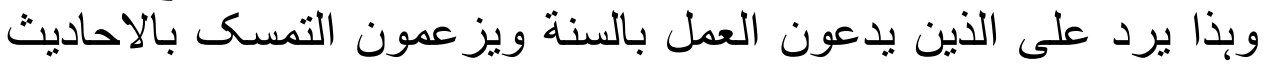

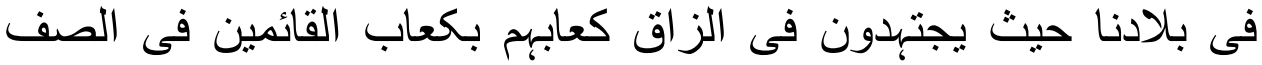

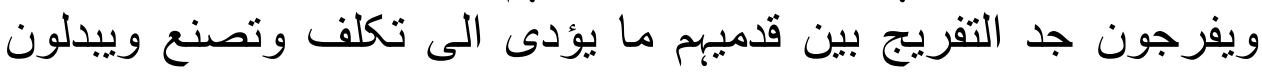

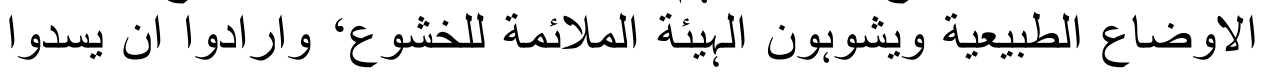

\footnotetext{
${ }^{31}$ Surath al Hajj:78

${ }^{32}$ Surath al Baqarah: 286

${ }^{33}$ Al Sahanpuri, Khalil Ahmad, Bazal al Majhood, v4, p 330, Idarath Taalifat Ashrafia, Multan.

${ }^{34}$ Al Usmani, Zafar Ahmad al Tahavi, A'ala al Sunan, v4, p.360, Darul Quran, Karachi, 1990.
} 
The Scholar Islamic Academic Research Journal

Vol. 6, No. 1 || January-June 2020 || P. 85-94

https://doi.org/10.29370/siarj/issue10ar17

الخلل و الفرج بين المقتدين فابقو الخلاً وفرجة واسعة بين قدميهم ولم

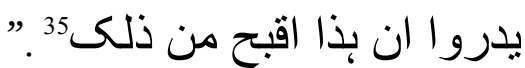

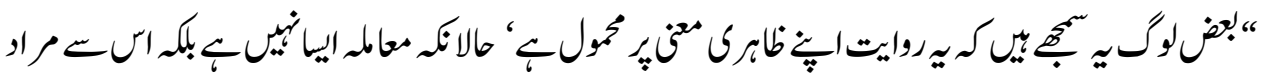

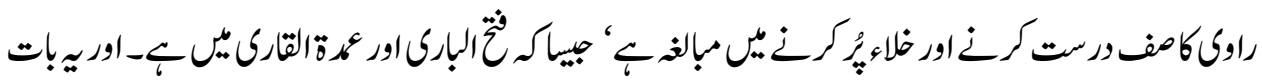

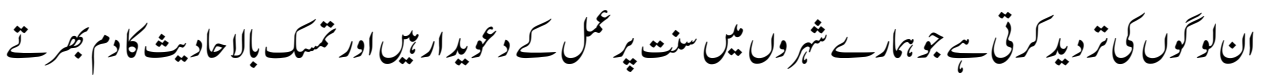

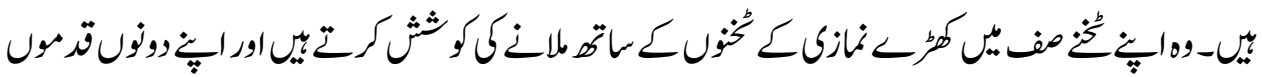

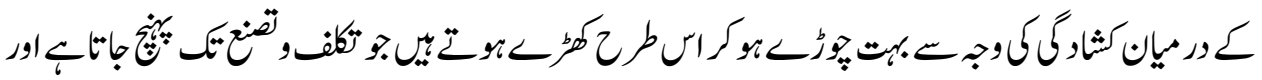

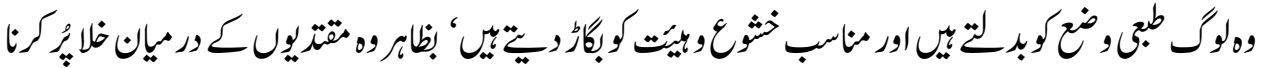

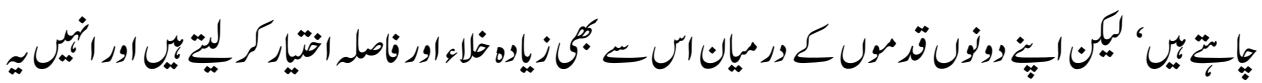

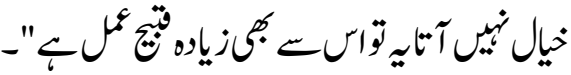

$$
\begin{aligned}
& \text { نماز ك اندرفاصله ركنا: }
\end{aligned}
$$

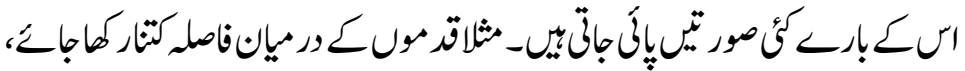

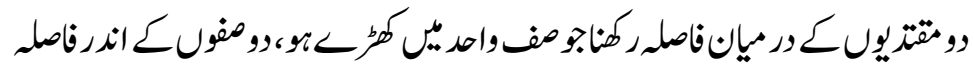

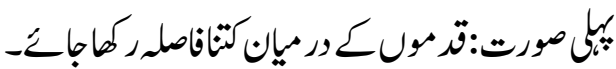

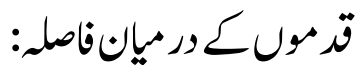
2: قرمولك ورميان فاصله:

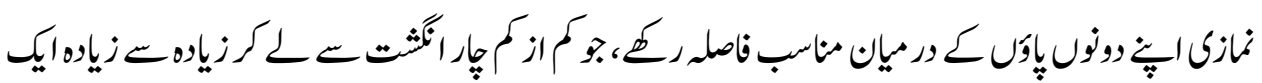

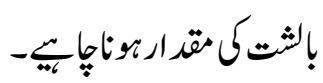
نق >نّ:

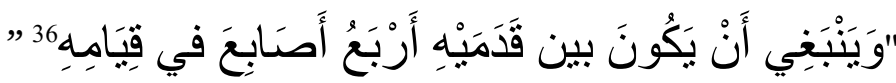

${ }^{35}$ Al Binori, Muhammad Yousuf al Binori, Ma'rif al Sunan Sharah Jamia' Tarmizi, v2, p 297,298, H M Saeed, Karachi. 
The Scholar Islamic Academic Research Journal

Vol. 6, No. 1 || January-June 2020 || P. 85-94

https://doi.org/10.29370/siarj/issue10ar17

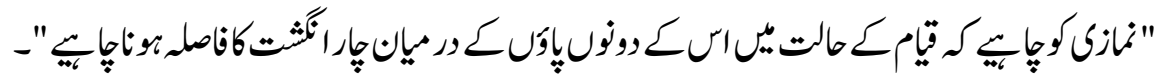

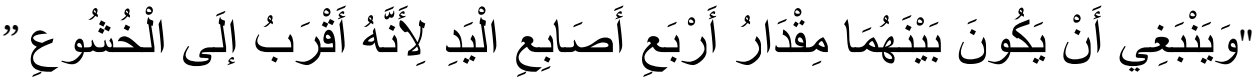

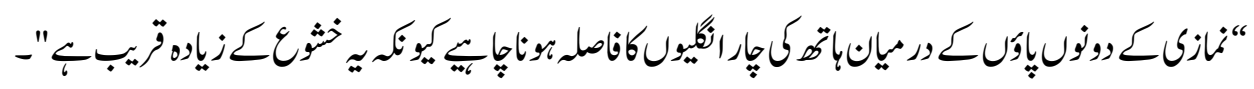

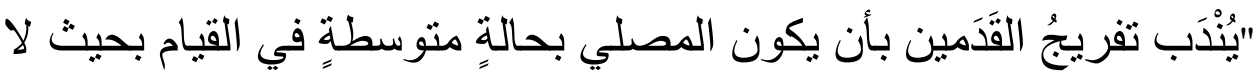

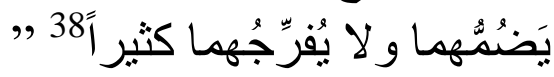

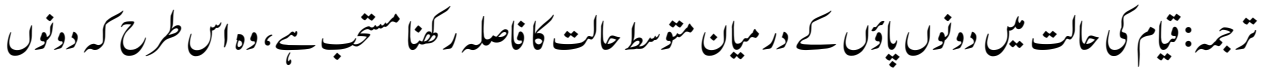

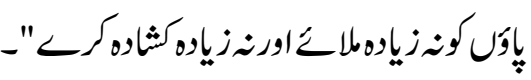

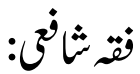

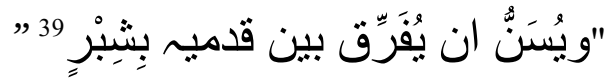

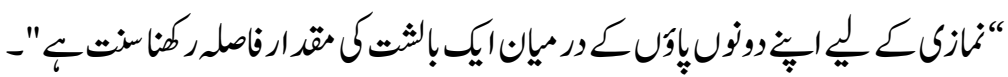
"ونَدُبَ التفريقُ بينهِما اع باربع اصـابعَ او بِشَبْرٍِ 40

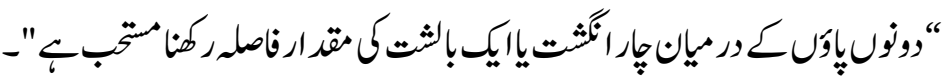
فق هن:

"وكان ابن عمر لا يفرج بين قدمبه و لا يمس إحداهما بالأخرى ولكن بين

$$
\text { ذللك لا يقارب و لا يباعد }
$$

${ }^{36}$ Al Jama', Fatawa A'lamgiri, v1, p. 81, Al Fasal al Salis fi sunan al Salah wa kifiatiha, Darul Isha', Karachi,

${ }^{37}$ Radul Mukhtar, lil Allama Ibne A'bidin, v2, P. 163, Bab Sifatul Salah.

${ }^{38}$ Fiqhul Ibadat, Maliki: p. 161, Markaz Darul Ma'rif al Islamia, Bairut, 1991.

${ }^{39}$ Al Damiati, Li Abi Bakar, Ea'natul Talibin: v3, p.247, Darul Yamama, Bairut, 1996.

${ }^{40}$ Al Ansari, Zikiria al Ansari al Shafaa'ee, Asna al Matalib fi Sharah Rozul Talib, v2, p.345, Maktaba al Yaminia, Egypt, 1980.

${ }^{41}$ Ibn e Qadama, Maqfiqul Din, Abu Muhammad Abdullah bin Ahmad bin Muhammad bin Qadamath al Muqdasi, Fasal: Ma yakraho min Harakatul Basar fil Salah al Riaz, Dar A'lim al Kutub, 1997. 


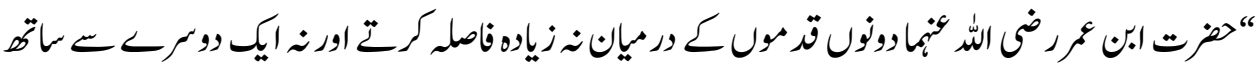

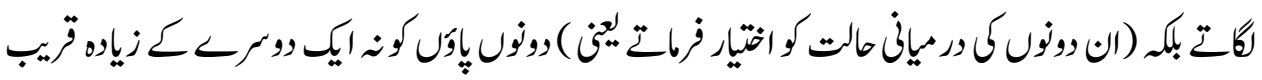

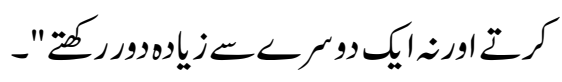

,

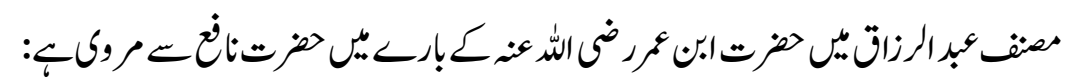
"أن بن عمر كان لا يفرسخ بينهما ولا يمس إحداهما الأخرى قال بين ذللك

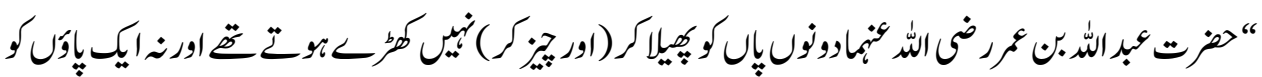

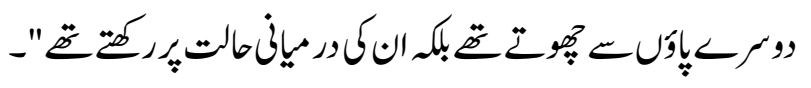

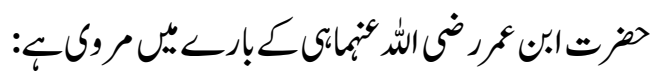

"وكان ابن عمر لا يفرج بين قدميه و لا يمس إحداهما بالأخرى ولكن بين

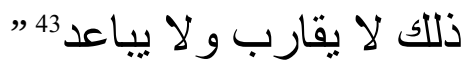

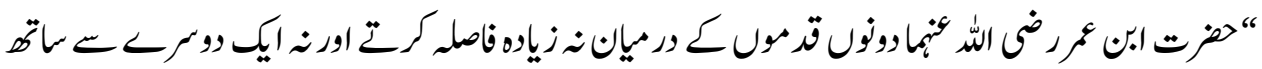

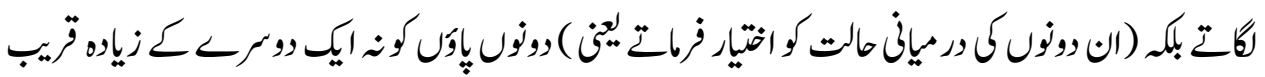

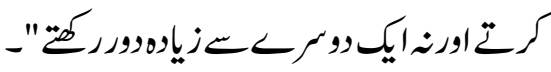

$$
\begin{aligned}
& \text { علامبرد الدينا ليني كيتمبي: }
\end{aligned}
$$

"يستحب للمصلي أن يكون بين قدميه في القيام [ قدر] أربع أصابع يديه ،

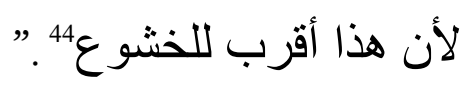

${ }^{42}$ al Sana'ni abdul Razaq, Musannaf Abdul Razaq, v2, p. 172, Bab al Tahrik fi Al Salah, Darul Isqafa, Bairut, 1992.

${ }^{43}$ Al Muqdasi, Abu Muhammad Abdullah bin Ahmad bin Muhammad bin Qadamath al Muqdasi, Fasal: Ma yakraho min Harakatul Basar fil Salah al Riaz, Dar A'lim al Kutub, 1997.

${ }^{44}$ Al Sujastani, Abi Dawood, Sharah Abi Dawood lil A'ini, v3, p. 354, Bab Waza' al Yamani al al Yusra fi Al Salah. 


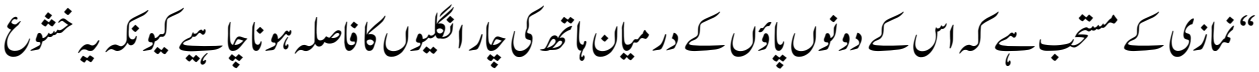

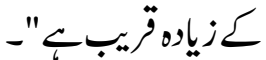

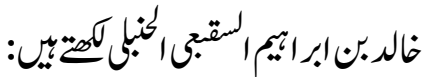

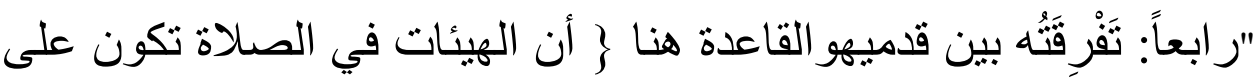
مقتضى الطبيعةولا تخالف الطبيعة إلا ما دل النص عليه\{ والوقوف

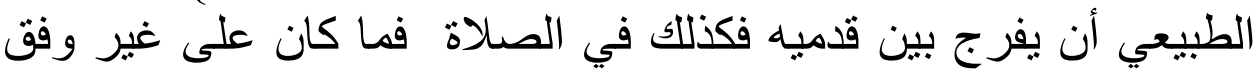

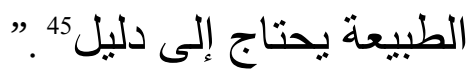

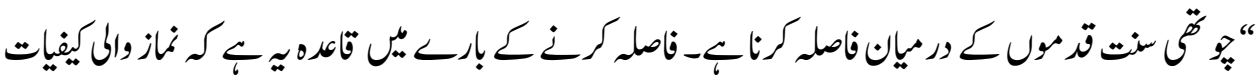

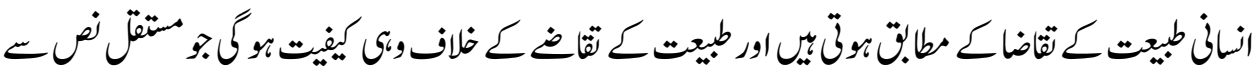

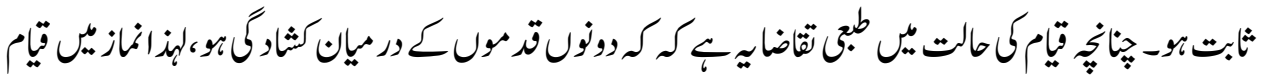

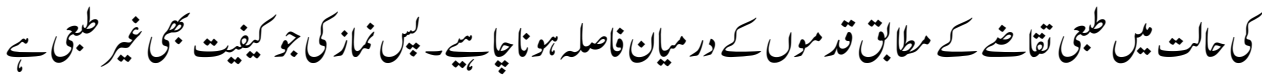

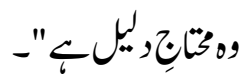
"قال الأثرم [احمد بن محمد بانى البغدادى] : (رأيت أبا عبد الله وهو

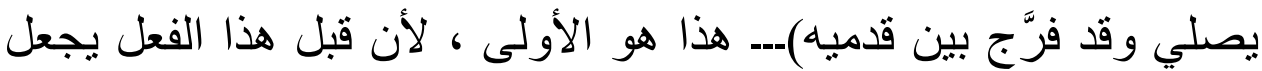
القدمين على طبيعتها ، وحيث لم يرد نص في في قدمبه هال القيام فإنه يبقيهما على الطبيعة

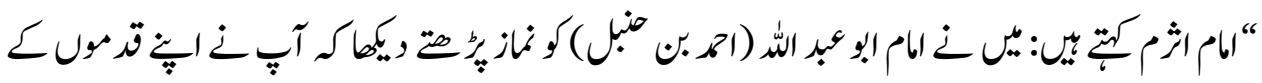

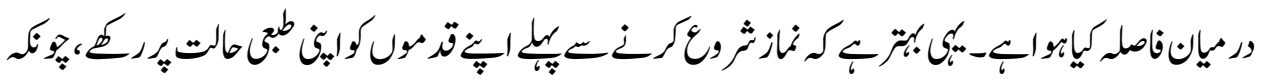

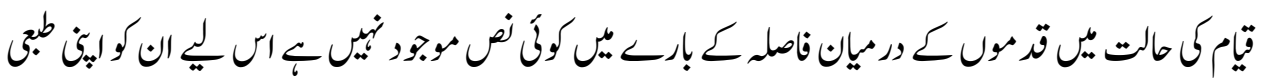

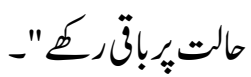

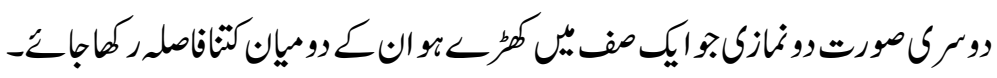

${ }^{45}$ Khalid al Saqaa'ee, al Qawl al Rajih ma'a al dalil Sharah Manarul Sabil, v2, p. 85, Darul Fikr, Bairut, 2000.

${ }^{46}$ Al Hamad, Hamad bin Abdullah, Sharah Zadul Mustanqia' lil Shiekh v5, p. 150, Darul Saqafa, Bairut, 1988. 


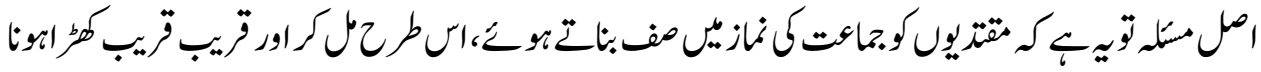

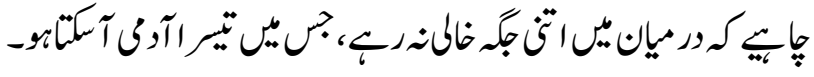

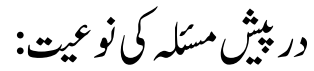

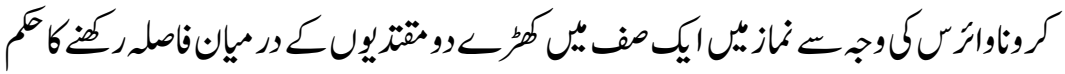

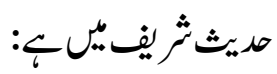

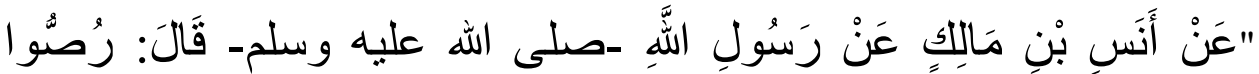

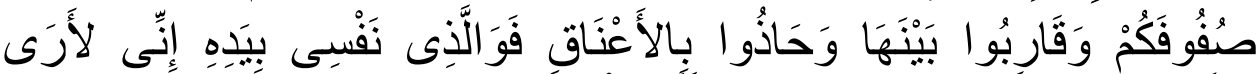

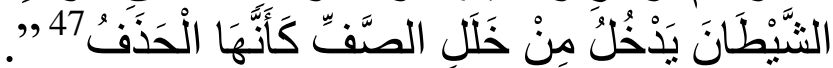

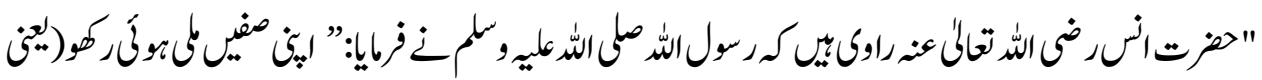

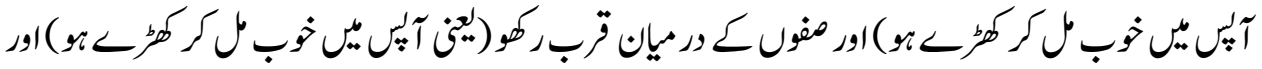

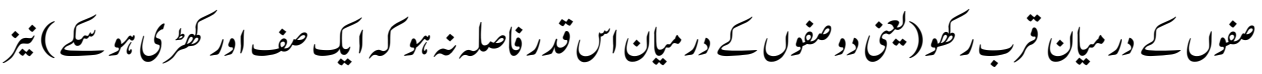

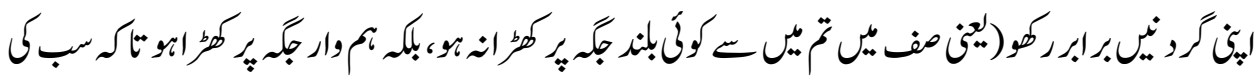

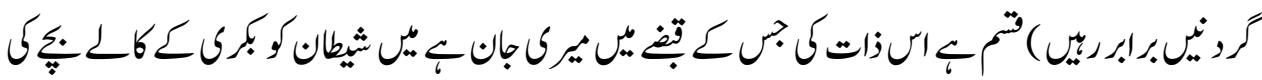

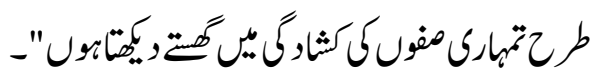

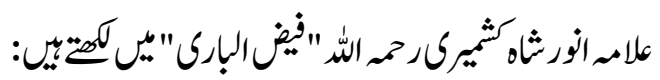

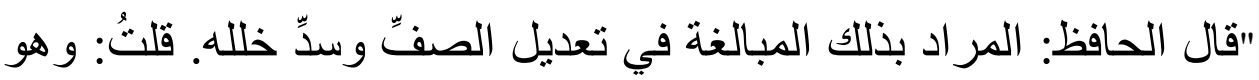

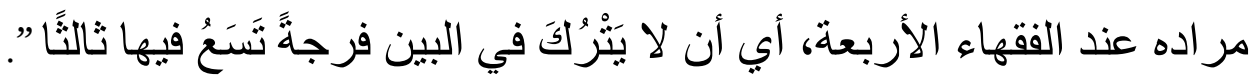

\footnotetext{
${ }^{47}$ Al Sujastani, Abi Dawood, Sharah Abi Dawood, Bab Taswiatul Sufoof.

${ }^{48}$ Faizul Bari al Sahihal Bukhari lil Kashmiri, v2, p. 302, Darul Kutub al A'ilmia, Bairut.
} 


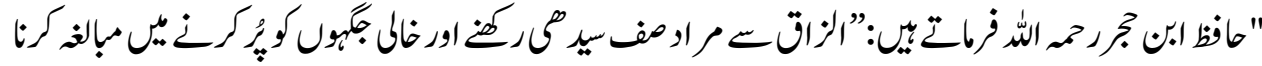

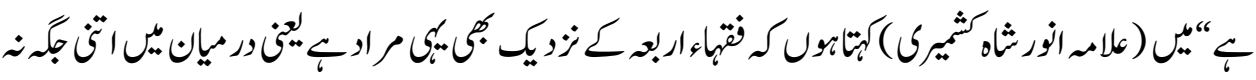

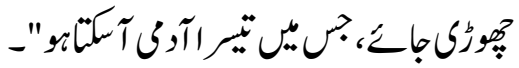

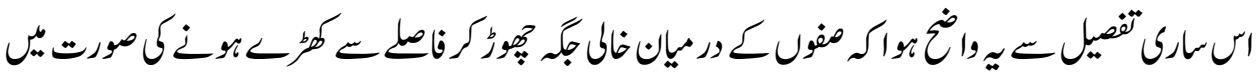

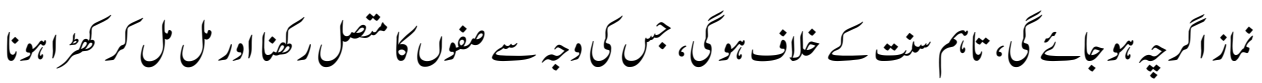

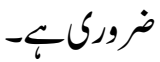

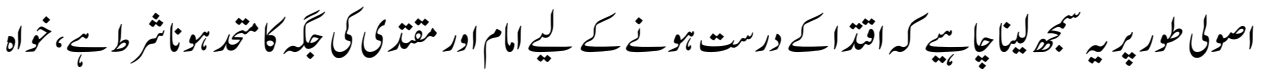

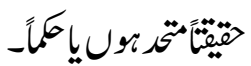

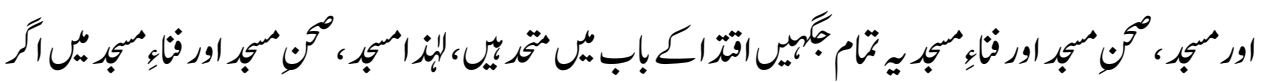

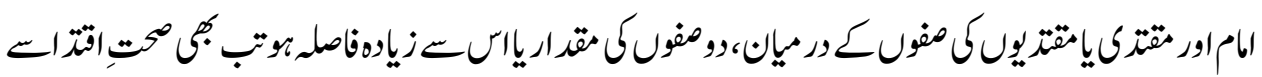

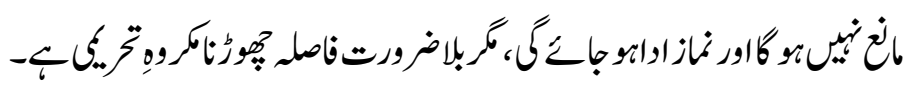

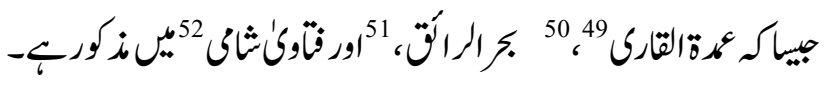

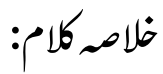

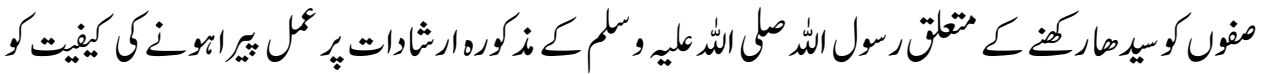

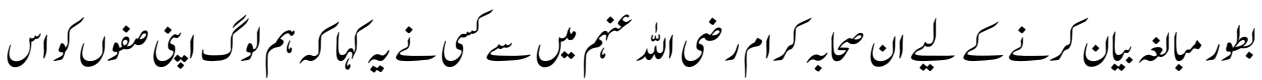

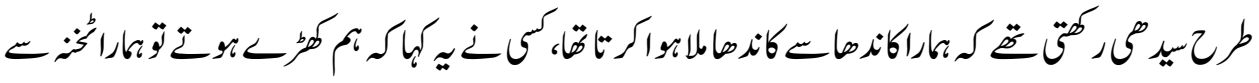

${ }^{49}$ Umdatul Qari, Sharah Sahih al Bukhari, lil Allama Badruddin, al A'ini v5, p. 254, Dar Ihia al Turas al Arabi.

${ }^{50}$ Al Tahavi, Ahmad bin Muhammad bin Ismail, Hashia al Tahtavi ala Maraqi al Falah: Bab al Imamath, Fasal fi Bayan al Ahaqq bil Imamath, p.306, Darul Kutub al Ilmia 2000.

51 Ibn e Najim, Zainul A'bidin, bin Ibrahim, al Bahar al Raiq, v1, p. 375, Darul Kitab al Islami.

${ }^{52}$ Radul Mukhtar lil Allama ibn e A'bidin, Babul Imamath, v1, p. 444, p. 585, Darul Fikr 
The Scholar Islamic Academic Research Journal

Vol. 6, No. 1 || January-June 2020 || P. 85-94

https://doi.org/10.29370/siarj/issue10ar17

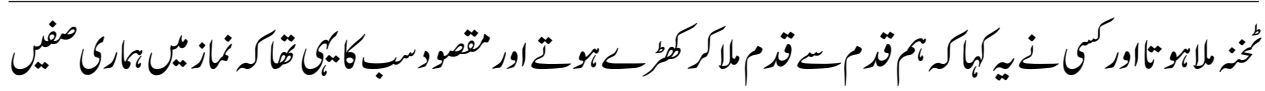

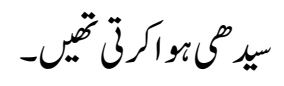

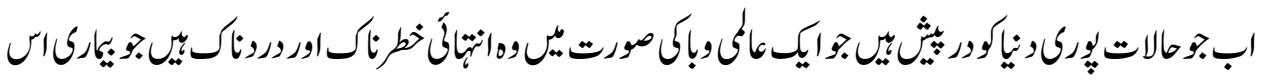

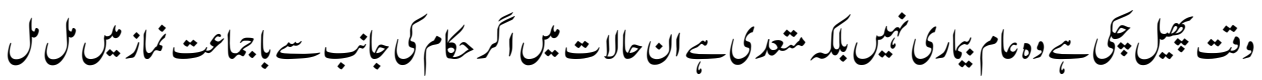

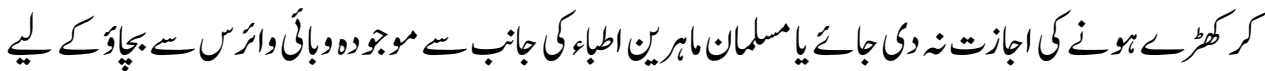

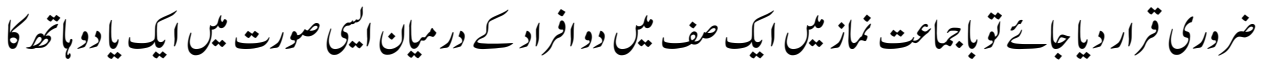

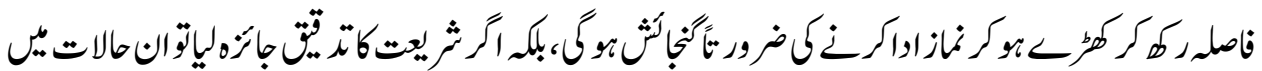

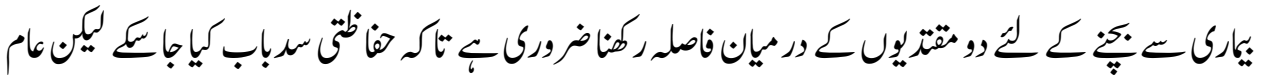

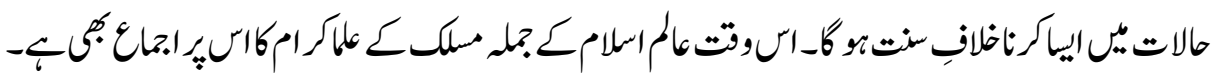

\section{(1) (1)(0)}

BY NC SA This work is licensed under a Creative Commons

Attribution-NonCommercial-ShareAlike 4.0 International (CC BY-NC-SA 4.0) 